\title{
Photoelectrocatalysis: principles, nanoemitter applications and routes to bio-inspired systems
}

\author{
H. J. Lewerenz, ${ }^{a}$ C. Heine, ${ }^{a}$ K. Skorupska, ${ }^{a}$ N. Szabo, ${ }^{b}$ T. Hannappel, ${ }^{b}$ T. Vo-Dinh, ${ }^{c}$ S. A. Campbell, ${ }^{d}$ \\ H. W. Klemm ${ }^{a}$ and A. G. Muñoz ${ }^{a}$
}

\author{
Received 3rd August 2009, Accepted 18th November 2009 \\ First published as an Advance Article on the web 14th April 2010 \\ DOI: $10.1039 / b 915922 n$
}

\begin{abstract}
An overview on processes that are relevant in light-induced fuel generation, such as water photoelectrolysis or carbon dioxide reduction, is given. Considered processes encompass the photophysics of light absorption, excitation energy transfer to catalytically active sites and interfacial reactions at the catalyst/solution phase boundary. The two major routes envisaged for realization of photoelectrocatalytic systems, e.g. bio-inspired single photon catalysis and multiple photon inorganic or hybrid tandem cells, are outlined. For development of efficient tandem cell structures that are based on non-oxidic semiconductors, stabilization strategies are presented. Physical surface passivation is described using the recently introduced nanoemitter concept which is also applicable in photovoltaic (solid state or electrochemical) solar cells and first results with $\mathrm{p}$-Si and p-InP thin films are presented. Solar-to-hydrogen efficiencies reach $12.1 \%$ for homoepitaxial InP thin films covered with Rh nanoislands. In the pursuit to develop biologically inspired systems, enzyme adsorption onto electrochemically nanostructured silicon surfaces is presented and tapping mode atomic force microscopy images of heterodimeric enzymes are shown. An outlook towards future envisaged systems is given.
\end{abstract}

\section{Background - introductory remarks}

The word 'catalyst' was coined by Berzelius in 1836 when he observed the oxidation of sulfur dioxide on hot platinum. ${ }^{1}$ About 60 years later, in 1894, Ostwald defined catalysis as the acceleration of a chemical reaction by a foreign substance that does not participate in the reaction. ${ }^{2}$ The famous example of the HaberBosch process $^{3,4}$ leads us to present day science where the application of surface science tools to understand and decipher catalytic processes has been pioneered by Ertl. ${ }^{5}$ The development of electrocatalysis is connected to research on fuel cells and an

${ }^{a}$ Institute for Solar Fuels and Energy Storage Materials, Helmholtz Center Berlin, Berlin, Germany

${ }^{b}$ Institute for Materials for Photovoltaics, Helmholtz Center Berlin, Berlin, Germany

'Fitzpatrick Institute for Photonics, Duke University, Durham, North Carolina

${ }^{d}$ School of Pharmacy and Medical Sciences, Portsmouth University, England, U.K. explicit definition of an electrocatalyst has been given by Grubb in $1963 .^{6}$

In a rather unrelated development, water electrolysis dates back to the 18th century when van Trostwijk and Deimel first observed the phenomenon. ${ }^{7}$ That was followed about a decade later by the report of Nicholson and Carlisle ${ }^{8}$ who achieved water dissociation using - at that time - novel batteries. Obviously, the developments in catalysis, electrocatalysis and water dissociation were historically far from being synchronized. It is not surprising that it took about 180 years before Fujishima and Honda published the first observation of light-induced water electrolysis ${ }^{9}$ using rutile $\mathrm{TiO}_{2}$ photoanodes, thereby strongly stimulating the field of photoelectrochemistry ${ }^{10-17}$ that resulted in the first industrially produced photoelectrochemical device which operated in the photovoltaic mode. ${ }^{18}$

The recent emphasis on light-induced generation of solar fuels has political as well as scientific reasons. The former relates to the findings and recommendations of the International Panel on Climate Change (IPCC) that were documented in its fourth report from the year 2007 urging immediate action on the

\section{Broader context}

The light-induced generation of fuels encompass processes such as light absorption, energy transfer to catalytic active sites and interfacial reactions at the catalyst-solution interfaces. These processes are discussed in the frame of the two principle routes envisaged for the realization of photoelectrocatalytic conversion systems: the bio-inspired single photon catalysis and the multiple photon inorganic cells. In particular, solar-to-hydrogen conversion systems based on $\mathrm{Rh}$ nanoparticles deposited on $\mathrm{p}-\mathrm{Si}$ and homoepitaxial p-InP films are analyzed. The adsorption of enzymes onto electrochemically nanostructured silicon is presented as a model system for development of biology based systems. 
reduction of atmospheric pollutants. ${ }^{19}$ Scientifically, the advances in nanosciences and the elucidation of basic mechanisms of photosynthesis have led to new insights on possible system architectures for light-induced water splitting. On the other hand, important fundamental aspects have remained unsolved despite intense research. ${ }^{20-22}$ This relates, for example, to the hitherto unexplained origin of the catalytic activity of platinum. This presently existing rather incoherent scientific situation finds its expression in the diversity of approaches that are pursued for solar fuel generation:

(i) monolithically integrated semiconductor-noble metal catalyst systems, particular as high-efficiency tandem structures, ${ }^{23-25}$

(ii) development of bio-inspired systems in which processes and material issues of photosynthesis are adapted; ${ }^{26}$

(iii) search for novel macromolecular catalyst materials based on the cluster structures of the reaction centers of photosynthesis; ${ }^{27}$

(iv) pursuit of combinatorial approaches for identification of novel catalytic and photoactive materials that overcome what has been called the "duality principle limitation" in photo(electro)catalysis, with regard to absorption and stability properties; ${ }^{28}$

Below, topics (i) and (ii) will be treated mostly. The extensive efforts in combinatorial research, particularly with regard to the use of metal oxides as catalytic absorbers ${ }^{29-33}$ would transcend the scope of this article which is focusing on the neighbouring scientific areas of our own work on catalysis with non-oxidic materials. Achieving the goal of multiple photon catalysis with oxides, for example, demands a much more advanced control of the materials science aspects of such compounds, as tandem-type structures have to be created. Other challenges presently encountered with oxides are charge transport, absorption spectra, doping and energetic alignments.

Similarly extensively pursued are research efforts in the development of photocatalysis systems that are based on macromolecular catalytic centers. ${ }^{34,35}$ Although a fascinating emerging field, it is too early to review it. The reader is made aware of respective energy frontier research center activities. ${ }^{36}$

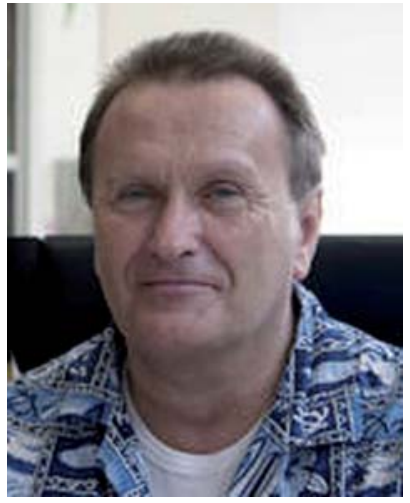

H. J. Lewerenz

Joachim Lewerenz is professor of physics at Technical University Berlin and adjoint professor for materials science and chemical engineering at North Carolina State University. He is deputy director of the Institute for Solar Fuels and Storage Materials at the Helmholtz Center for Materials and Energy, Berlin. His research interests are photoelectrochemistry, surface science and solar energy conversion. He has pioneered research in chalcopyrite solar cells, and recently, nanoemitter conversion devices. He has authored three books, holds 15 patents, and has published over 230 research articles.

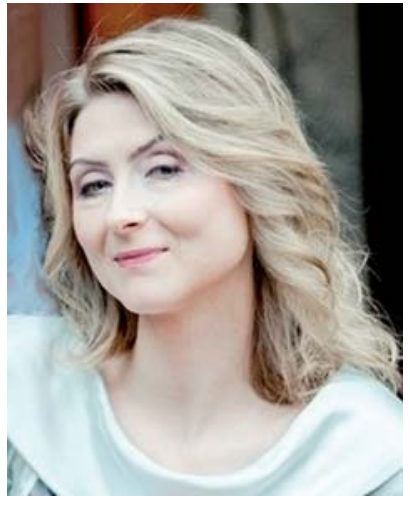

K. Skorupska
Katarzyna Skorupska received her PhD at Poznan University of Technology working with solid polymer electrolytes. Afterwards, she joined the Helmholtz Center Berlin. She is habilitating in chemistry at Warsaw University, Poland. Her research interests are surface chemistry, solar energy conversion and bioelectrochemistry. She has lecturing appointments with the University of Warsaw, Technical University Berlin, and Brandenburgisch Technical University Cottbus, Germany.

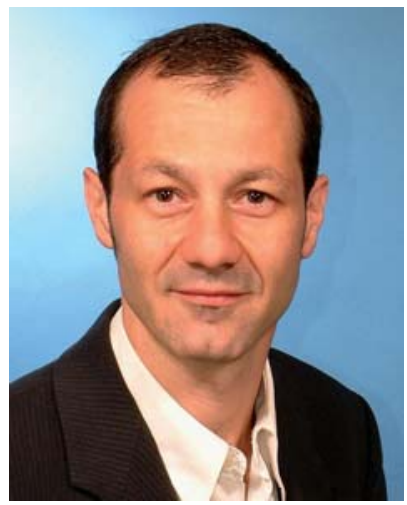

T. Hannappel
Thomas Hannappel is provisional head of the Institute "Materials for Photovoltaics" at the Helmholtz Center Berlin since 2005 and lecturer at the Free University. He received his PhD in physics at the Technical University Berlin with studies on photo-induced charge carrier separation in dye solar cells, which he performed at the FritzHaber-Institute, and received his state doctorate at the Free University of Berlin. In 2003/04 he conducted research on silicon/III-V-interfaces at NREL. His current investigations are focused on high-performance solar cells and critical interfaces.

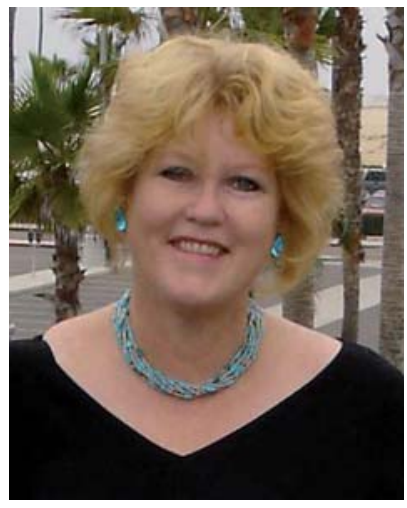

S. A. Campbell
Dr Sheelagh Campbell is director of the Applied Electrochemistry Group at the University of Portsmouth. She received her PhD from the University of Portsmouth, after which she spend 11 years at the University of Southampton working as a research scientist within the Wolfson Centre for Electrochemical Science. Her interests include interdisciplinary research and development projects in applied electrochemistry and bioelectrochemistry, with particular emphasis on electroactive polymers, corrosion and protection of metals, conservation and STM and AFM imaging of biomolecules. 
The use of efficient solid state photovoltaic solar cells in combination with electrolysers has been discarded here due to practicability arguments, ${ }^{37}$ although the collection of lightinduced hydrogen from envisaged fields of fuel generating electrochemical cells clearly poses a chemical engineering problem.

\section{Basic processes of photo(electro)catalysis}

An overview of the contributing processes to photo(electro)catalysis is shown in Fig. 1. For clarity, the individual processes of photon absorption, excitation energy transfer and interfacial reaction at the solution boundary have been separated. Within this representation, light absorption is followed by the transfer of the photonic energy to a catalytically active site, where the water dissociation reaction occurs. The individual steps of this sequence comprise a multitude of phenomena that are schematically expressed in Fig. 2. Absorption can occur in crystalline material, thin epitaxial, polycrystalline or amorphous films, in clusters, quantum dots, dyes and macromolecules or in nanocomposite materials. A few possibilities are shown in the upper right hand side of Fig. 2. The photophysics of the absorption process include the standard processes known in semiconductors, ${ }^{38}$ but they also encompass processes such as multiple exciton generation ${ }^{39}$ and singlet fission. ${ }^{40}$ The excitation energy transfer from the absorber to the catalyst is usually assumed to be an electronic conduction process, which, in less ordered semiconducting materials, could also be due to a hopping mechanism and dispersive transport. ${ }^{41,42}$ Fig. 1 shows schematically the motion of light-induced excess (minority) electrons in the conduction band of a p-type semiconductor to its surface. Also shown are alternative processes that have been identified in photosynthesis and organic devices; whereas the Dexter electron exchange mechanism, ${ }^{43}$ which results in hopping of light-generated excitons, necessitates a rather close spatial arrangement of the conductive units, the transmitter-antenna mechanism for energy transfer by coulombic interactions after Förster ${ }^{44}$ occurs over comparably large distances, with Förster

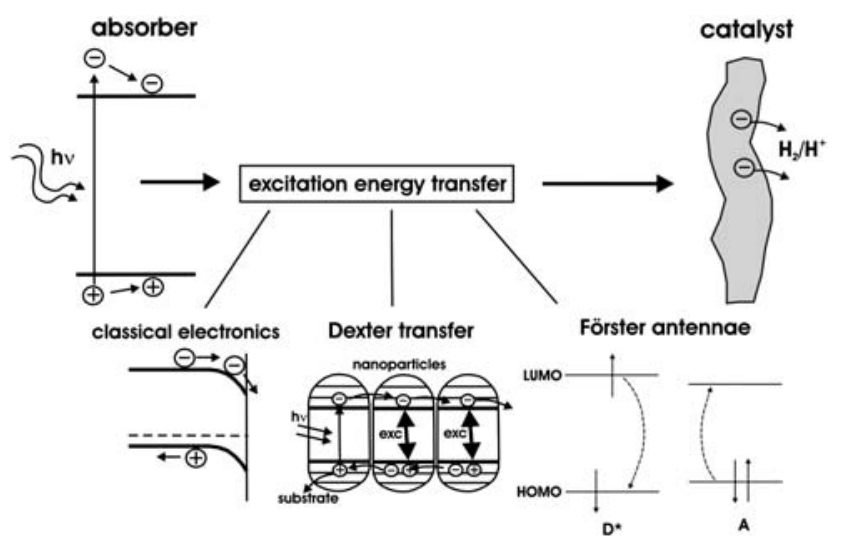

Fig. 1 Overview of contributing processes to light-induced water splitting at a photocathode, resulting in hydrogen generation; exc is used as abbreviation for exciton, $\mathrm{D}^{*}$ and $\mathrm{A}$ denote excited donor and acceptor molecules, respectively (see also text).

radii of the order of $5-10 \mathrm{~nm} .{ }^{44}$ The Dexter energy transfer rate is given by

$$
k_{E T}=K J e^{-\frac{2 r_{D A}}{L_{A}+L_{D}}}
$$

Eqn (1) describes excitation energy transfer electron exchange. $K$ is an orbital interaction related prefactor, $J$ denotes a normalized spectral overlap and the exponent contains $r_{\mathrm{DA}}$, the donor-acceptor distance related to the sum of the van der Waals radii, $L=L_{\mathrm{A}}+L_{\mathrm{D}}$, of the contributing molecules/atoms. Fig. 1 shows a rough sketch of the process: the donor molecule in its ground state is photoexcited, which results in exciton formation. If the energetic relations between upper and lower state (LUMO and HOMO for molecular states) are aligned such that the electron of the excited donor can be transferred to the acceptor unoccupied level and the light-generated hole on the donor becomes occupied by an electron from the acceptor, the exciton has moved to the right. Eventual exciton

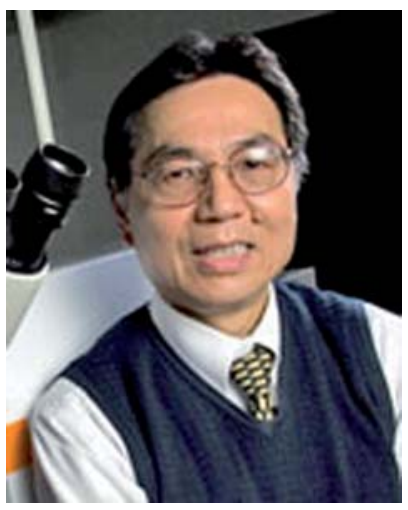

T. Vo-Dinh
Tuan Vo-Dinh, a pioneer in the field of photonics, is R. Eugene and Susie E. Goodson Distinguished Professor in biomedical engineering and chemistry and director of the Fitzpatrick Institute for Photonics at Duke University since 2006. Vo-Dinh earned a PhD in biophysical chemistry from the ETH (Swiss Federal Institute of Technology) in Zurich, Switzerland. Vo-Dinh has developed a range of instruments and devices aimed at advancing scientific inquiry and detecting chemical exposure and disease. Vo-Dinh won seven R\&D 100 Awards for his inventions and the Gold Medal Spectroscopy Award from the Society for Applied Spectroscopy.

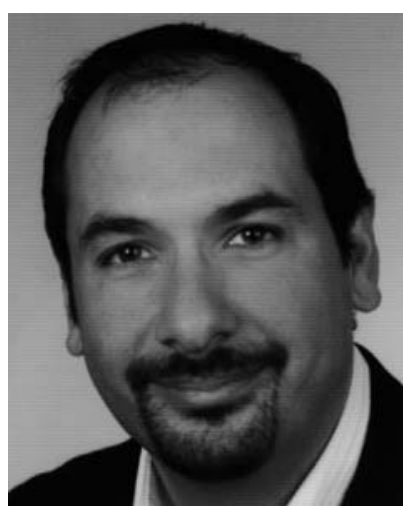

A. G. Muñoz
Andrés G. Muñoz is a senior researcher at the Helmholtz Center Berlin and lecturer at the Brandenburgisch Technical University Cottbus. He received his PhD in Materials Science at the University del Sur, Argentina. He has been distinguished with an $A$. von Humboldt fellowship in 2004 and has performed research in basic and applied electrochemistry at the Research Center Jülich, the University of Erlangen and the Heinrich-Heine University of Düsseldorf. His current investigations are focused on surface chemical and electronic processes on conditioned semiconductor-electrolyte interfaces for solar applications. 


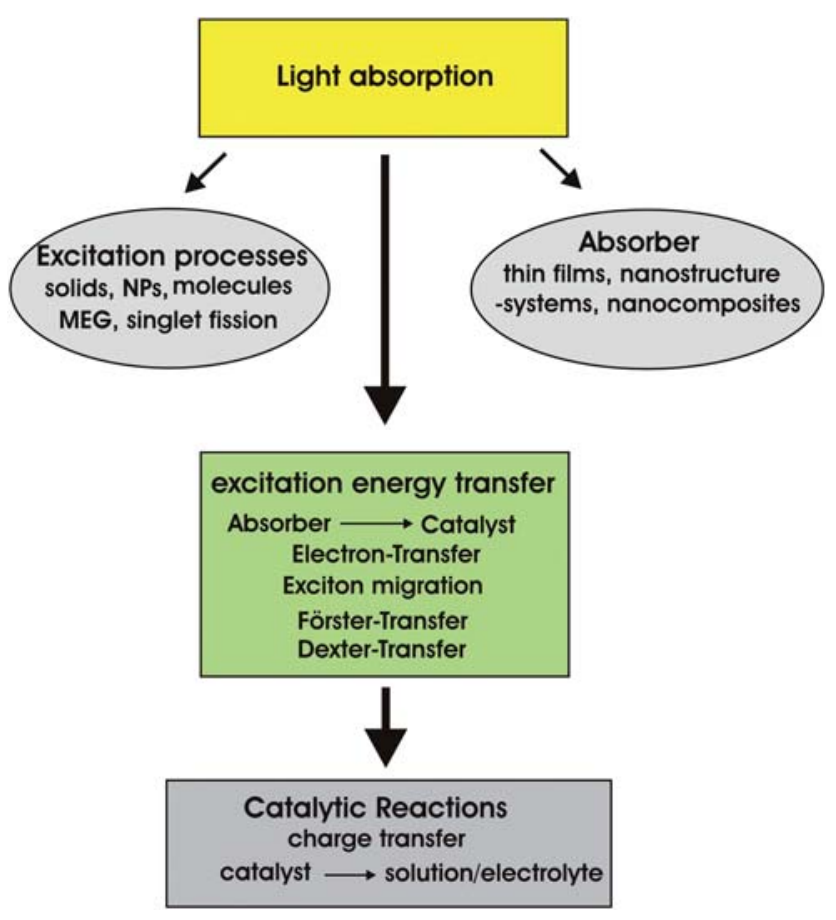

Fig. 2 Overview of the process sequence and multitude of scientific parameters in light-induced water splitting (see text); MEG: multiple exciton generation; NPs: nanoparticle(s).

dissociation, for example due to a chemical potential gradient as in dye sensitized solar cells, ${ }^{45,46}$ then results in electron transfer to the catalyst.

The Förster process is described by quantum mechanical transition dipole interactions in the weak perturbation limit (Fermi's golden rule approach). This non-radiative transfer of electronic excitation from a donor molecule, $\mathrm{D}$, to an acceptor molecule, A, can be written as

$$
\mathrm{D}^{*}+\mathrm{A} \rightarrow \mathrm{D}+\mathrm{A}^{*}
$$

The initial process, the recombination of the excited donor singlet that excites the acceptor, is shown in Fig. 1. Fig. 3 shows the Förster excitation energy transfer process in more detail,

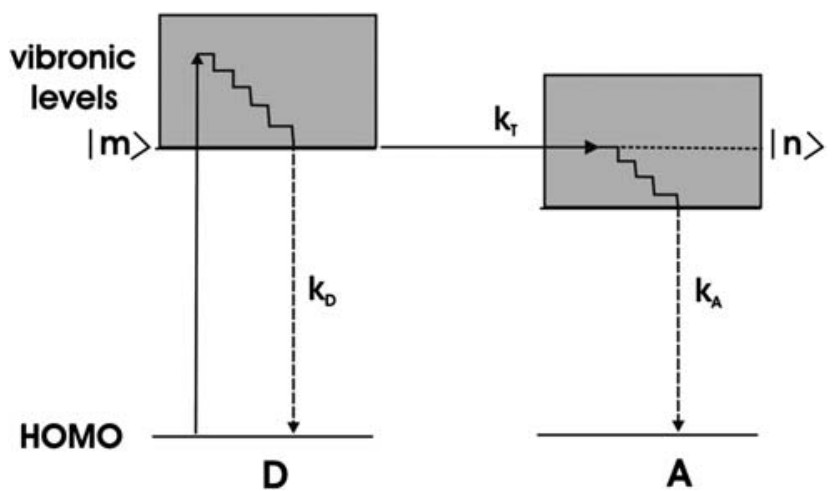

Fig. 3 Schematic of fluorescence and excitation processes of Förster transfer, including vibronic levels and decay constants (for term definitions, see text). including vibronic levels; $k_{\mathrm{T}}$ denotes the so-called Förster transfer rate, $k_{\mathrm{D}}$ and $k_{\mathrm{A}}$ are decay constants of the donor and acceptor states. The resonance character of the process is indicated in the Figure by the iso-energetic energy transfer and in eqn (3) by the $\delta$ function. The transfer rate is given by the interaction matrix element $V_{\mathrm{mn}}$ that connects initial $(\langle m|)$ and final $(|n\rangle)$ states:

$$
k_{T}=4 \pi^{2}\left|V_{m n}\right|^{2} \delta\left(\nu_{n}-\nu_{m}\right)
$$

Since the mechanism is a dipole-dipole interaction of the transition dipole moments, the interaction matrix element becomes

$$
V_{m n}=\frac{f^{2}}{4 \pi \varepsilon_{0} \varepsilon r^{3}} \mu_{m} \mu_{n} \kappa
$$

where $\mu_{\mathrm{m}}$ is the transition dipole moment from the donor ground state to the $|m\rangle$ state and $\mu_{\mathrm{n}}$ is the equivalent for the acceptor, $\kappa$ is an orientation factor that contains the relative alignment of the dipoles, $r$ is the $\mathrm{D}-\mathrm{A}$ distance and $f$ is an effective field factor. ${ }^{47}$ The emission spectrum of the donor and the absorption spectrum of the acceptor contain Franck Condon overlap factors, $\mathrm{S}$, with $\mu_{\mathrm{m}}=\mathrm{S}_{\mathrm{m}} \mu_{\mathrm{D}}$ and $\mu_{\mathrm{n}}=\mathrm{S}_{\mathrm{n}} \mu_{\mathrm{A}}$, where $\mu_{\mathrm{D}, \mathrm{A}}$ denote the electronic transition moments. As a result, the transfer rate can be expressed in terms of the decay rate, $k_{\mathrm{D}}$, and the so-called Förster radius, $R_{0}$ (distance at which the efficiency of energy transfer is $50 \%$ ), is given by

$$
R_{0}^{6}=8.8 \times 10^{17} \frac{\kappa^{2}}{n^{4}} J
$$

where $J$ denotes the overlap integral that contains the donor fluorescence and the acceptor absorption spectra. The rate $k_{\mathrm{T}}$ becomes

$$
k_{T}=k_{D}\left(\frac{R_{0}}{R}\right)^{6}
$$

Experimental estimates of the Förster rate in energy transfer from the light harvesting complex (LH2) unit B 800 to B 850 show pronounced discrepancies with the predictions of single chromophoric Förster resonance energy transfer (FRET) theory. ${ }^{48}$ The observed deviations by factors of between 5 and 10 have led to a reformulation of the theory for energy transfer in photosynthesis, ${ }^{49}$ resulting in a so-called multichromic FRET that includes disorder and temperature.

Photoelectrocatalytic systems can consist either of an absorber that is catalytically active by itself or of a structure where light absorption and catalytic activity is spatially separated (see also Fig. 1), as shown in Fig. 4. Fig. 4a shows a schematic where a thin film catalytic absorber has been deposited on a conductive substrate. Upon illumination, the light-induced excess minority carriers can migrate (drift and diffusion) to the phase boundary with the electrolyte, where the catalytic reaction occurs on the absorber surface. In the second approach, the light-induced charge carriers have to migrate to the interface between absorber and catalyst and the fuel evolving reaction occurs at the catalyst/ solution interface (Fig. 4b). In Fig. 4, a reduction reaction $\left(\mathrm{H}_{2}\right.$ evolution, $\mathrm{CO}_{2}$ reduction) has been chosen. The energy levels of the catalyst material, which appears as a film covering the 
(a)

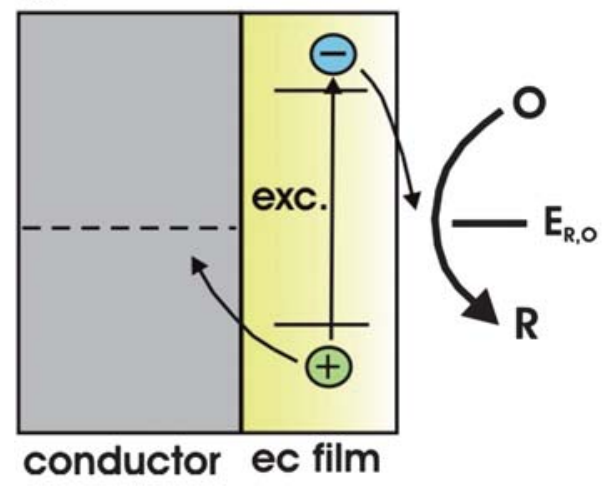

(b)

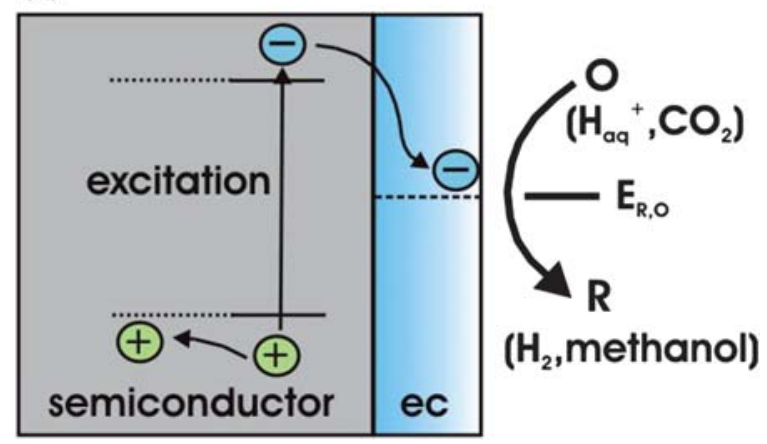

Fig. 4 Schematic of two configurations of photo(electro)catalytic devices; (a) the absorber material itself is catalytic (ec: electrocatalytic); (b) the absorber is covered by a catalyst.

surface, are represented on an energy scale in Fig. 4b. Actually, such catalysts can be micro- to nanoparticles and it would help the functioning of these devices if the contact between catalyst and absorber is rectifying. A problem with metal catalysts can arise from the existence of metal induced gap states (MIGS), ${ }^{50}$ leading to Fermi level pinning ${ }^{51}$ and thus to reduced attainable photovoltages.

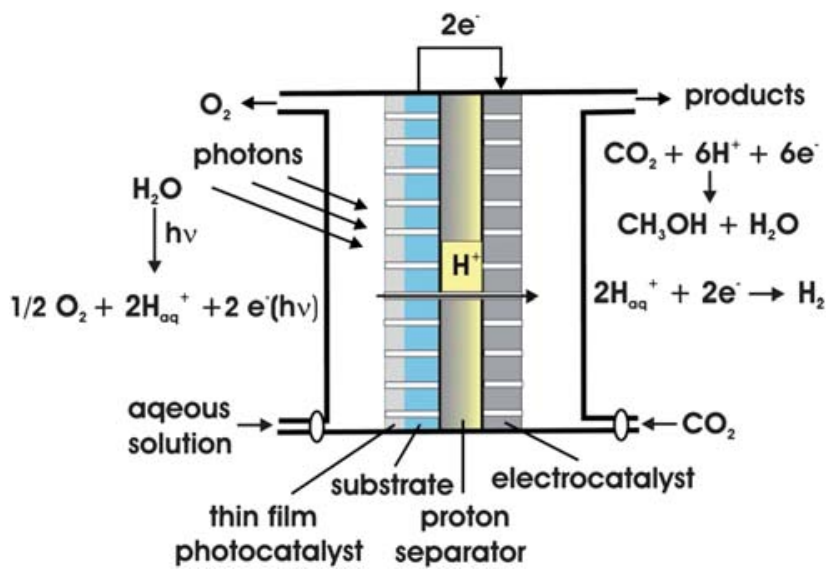

Fig. 5 Envisaged light-induced water splitting device where, at the cathode, $\mathrm{CO}_{2}$ reduction to methanol has also been included; the photoactive part is the anode that consists of a catalytic absorber (configuration of Fig. 4a) (see the text). ${ }^{44}$
A model of a device for light-induced water splitting is presented in Fig. 5, adapted from ref. 52. The system consists of a catalytic photoanode absorber on a substrate where oxygen evolution from water occurs, a proton separator membrane, such as Nafion, and an electrocatalytic film for the cathode reaction. The protons, generated in the photoanodic process, can diffuse to the cathode side, where either hydrogen evolution or carbon dioxide reduction can occur. The latter has been shown for the reaction to methanol, which is a 6 electron transfer reaction. One might also consider the reduction to formic acid, according to

$$
\mathrm{CO}_{2}+2 \mathrm{H}_{\mathrm{aq}}{ }^{+}+2 \mathrm{e}^{-} \rightarrow \mathrm{HCOOH}
$$

at a potential of $-0.61 \mathrm{~V}$ at $\mathrm{pH} 7$, because of the possibility of using formic acid in fuel cells. ${ }^{53}$ The reaction

$$
\mathrm{CO}_{2}+\mathrm{e}^{-} \rightarrow \mathrm{CO}_{2}^{-}
$$

is characterized by a large activation energy as it occurs at $-1.9 \mathrm{~V}$. Therefore, developing and employing multi-electron transfer routes, possibly using transition metal complexes, appears worthwhile.

\section{Stability issues}

Stability can be viewed as the key challenge in photoelectrochemical solar energy conversion. Because semiconductors are, in general, not thermodynamically stable at the reactive electrolyte interface, ${ }^{54,55}$ stabilization strategies have been developed. The existing approaches can be roughly divided into four categories, as visualized in Fig. 6: (a) chemical passivation of the surface, as, for instance, by H-termination ${ }^{56-58}$ or methylization; 59,60 (b) stabilization by energy band structure properties; this has been found in transition metal chalcogenide materials where the upper valence band and the bottom of the conduction band are composed predominantly of metallic d-states. ${ }^{61}$ Photonic absorption results, after excess carrier thermalization, in predominantly intrametallic electron-hole pairs near the surface. Thus, the metal-chalcogen bond remains largely unaffected, which suppresses photocorrosion; (c) kinetic stabilization occurs if the redox reaction (process 1 in Fig. 6c) is excessively faster than the corrosion reaction (process 2, 2a) and surface recombination (process 4). Process 3 refers to the electrodeposition process of noble metals onto $\mathrm{Si}$ which will be treated further below; (d) physical stabilization necessitates, in principle, a conformal ultrathin coating on the surface that inhibits ion transfer, but simultaneously allows efficient electron transfer. A few successful systems have been developed. ${ }^{62-65}$ They are mostly characterized by specific interactions of the semiconductor surface with electrolyte components. The more general approach needed for physical stabilization is presently evolving by employing ALD methods. ${ }^{66}$

The nanoemitter concept is based on physical passivation and presently uses films formed upon photocorrosion as passive layers. ${ }^{67}$ It was first developed for $\mathrm{n}$-Si for operation in the photovoltaic mode of an electrochemical solar cell, ${ }^{68}$ yielding efficiencies above $10 \% .{ }^{69}$ Although the concept is particularly intriguing with regard to stabilization of photoelectrochemical systems, it can also be applied in solid state solar devices. 
(a)

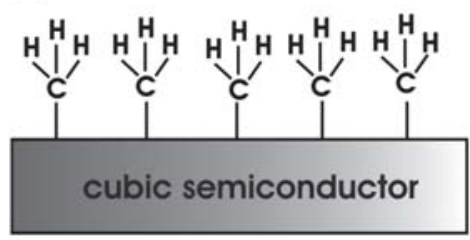

(b)

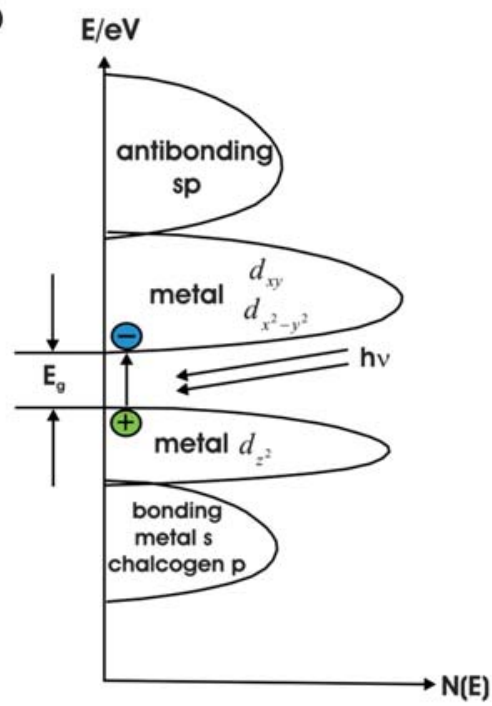

(c)
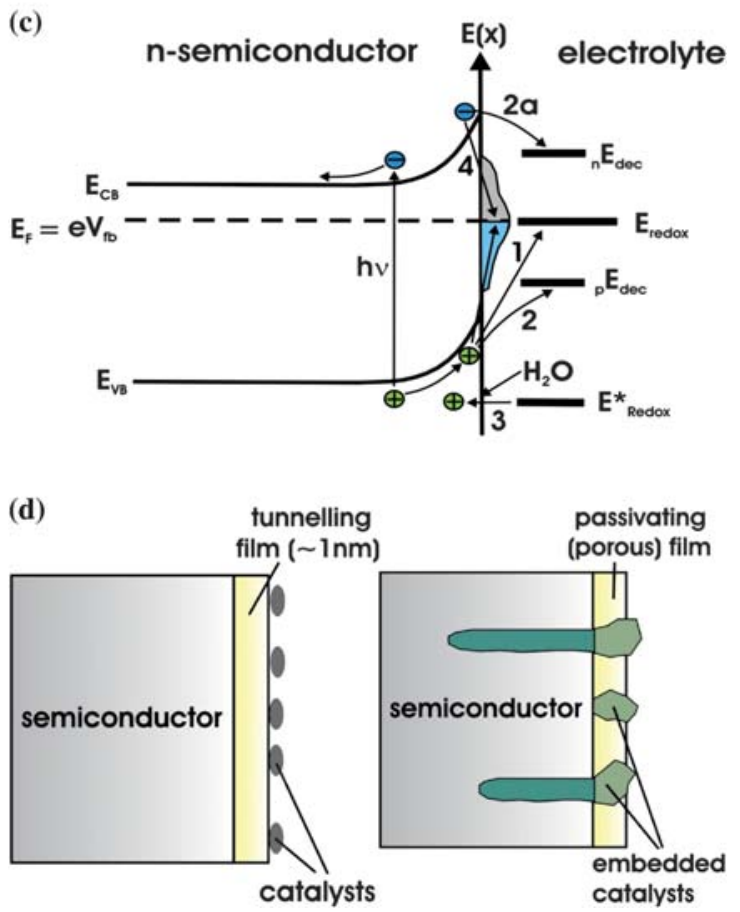

Fig. 6 Stabilization strategies for liquid junction solar cells; (a) chemical passivation, (b) corrosion resistivity by bandstructure properties, (c) kinetic stabilization; processes: (1) redox reaction, (2, 2a) anodic and cathodic decomposition, respectively, (3) hole injection into the semiconductor valence band, (4) surface/interface recombination; (d) physical passivation; left: passivation by ultrathin conformal passive layer; right: nanocomposite structure with a nanoporous passive layer.
A schematic of the operational principle of a nanoemitter device is shown in Fig. 7. For intelligibility, a top view (Fig. 7a) and a side view (Fig. 7b) are displayed. When in contact with redox electrolytes, the Fermi level of the metallic nanoemitters adjusts to that of the solution. If the metal nanoislands form rectifying junctions without Fermi level pinning, the system is characterized by a rectifying junction between the electrolyte and the semiconductor absorber. The decoupling of the metal/semiconductor junction, which is often impeded by MIGS, ${ }^{49,70}$ can be achieved by spatial separation introducing, for example, an ultrathin interfacial film that inhibits interpenetration of evanescent metal states into the semiconductor energy gap.

Upon illumination, the transparent passive layer transmits the sunlight, which is absorbed in the underlying semiconductor. If the relationship for the distance, $\mathrm{D}$, of the nanoemitters, the
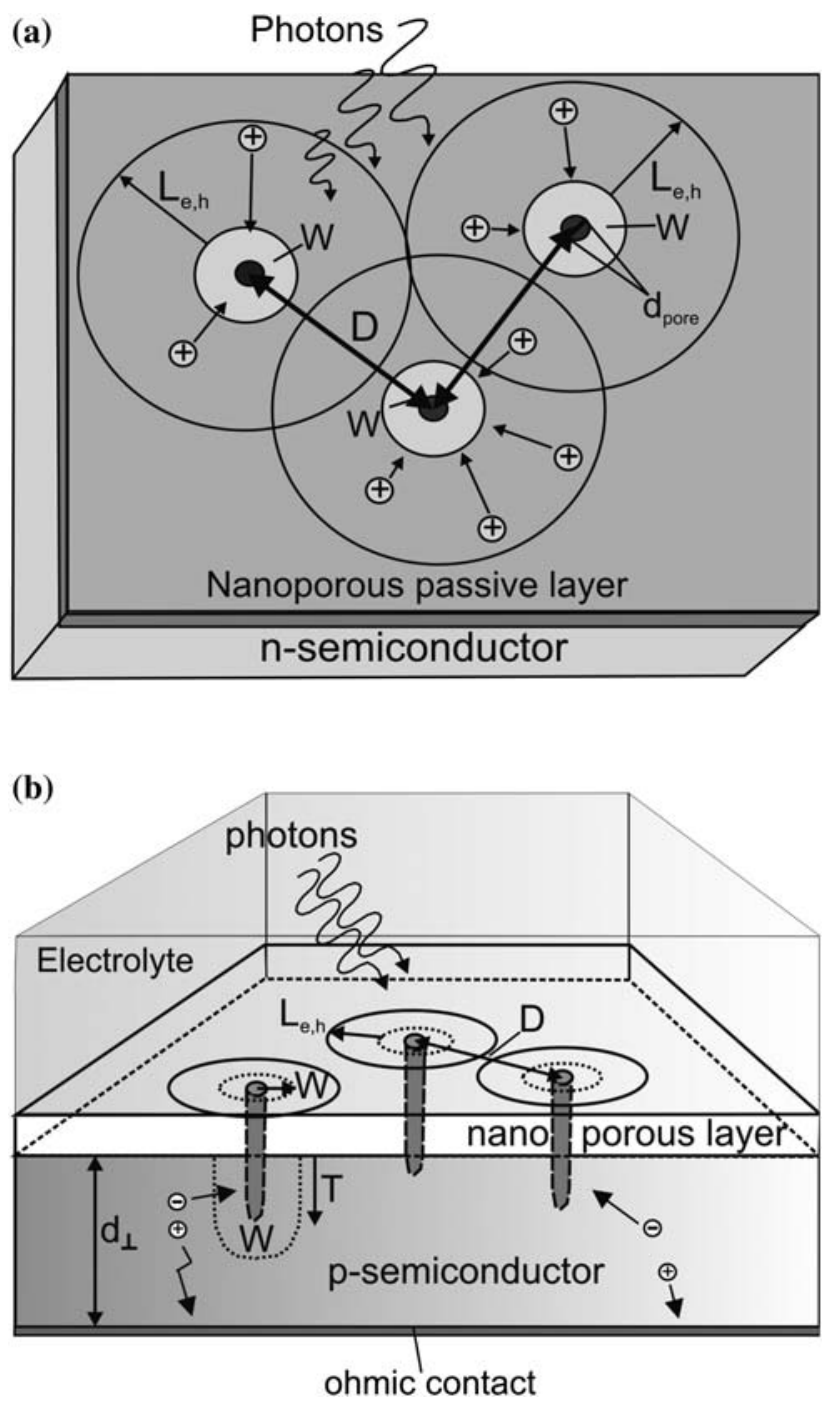

Fig. 7 Operation principle of nanoemitter solar cells; (a) top view for an n-type semiconductor; D: distance between nanoemitters, $d_{\text {pore }}$ : diameter of nanopores filled with (metal) emitter material; W: space charge layer width around the emitters; $L_{\mathrm{e}, \mathrm{h}}$ : minority carrier diffusion length for electrons (p-type semiconductors) or holes (n-type, as in this Figure); (b) side view of the nanoemitter structure for a $\mathrm{p}$-type material; $\mathrm{T}$ : depth of the nanoemitters relative to the absorber surface; $d_{\perp}$ : absorber thickness (see also text). 
minority carrier diffusion length, $L_{\mathrm{e}, \mathrm{h}}$, the nanoemitter radius, $r$, and the space charge region around the emitters, $W_{\mathrm{S}}$, of

$$
D \leq \sqrt{2}\left(L_{e, h}+r+W_{S}\right)
$$

holds, efficient lateral carrier collection through the nanoemitters occurs (Fig. 7a). The extension of the semispherical space charge layer, $W_{\mathrm{S}}$, is given by its radius, $r$, and the extension of the planar layer due to doping and dielectric constant is given by:

$$
W_{S}=\left(\frac{3}{2} r W^{2}\right)^{1 / 3}
$$

Condition (9) demands that the circles with radius $r+W_{\mathrm{S}}+$ $L_{\mathrm{e}, \mathrm{h}}$ overlap such that the electrode surface area is completely covered by the circles. The red sensitivity of the structure depends on the penetration of the nanoemitters into the absorber material (Fig. 7b) and the according relation for efficient excess minority carrier collection reads

$$
d_{\perp} \leq T+W_{S}+\frac{L_{e, h}}{2}
$$

For small metal catalyst particles in the size range below $50 \mathrm{~nm}$ and for diffusion lengths of $5 \mu \mathrm{m}$, typical for thin film absorber solar materials, even expensive metals, such as $\mathrm{Pt}, \mathrm{Ru}$ or $\mathrm{Ir}$ and $\mathrm{Rh}$, do not represent a cost restriction factor. This is due to the extremely low material amount needed to collect the lightinduced carriers. Assuming medium size cubic metal islands with $50 \mathrm{~nm}$ dimensions, $4 \times 10^{10}$ nanoemitter islands are needed to efficiently collect carriers from $1 \mathrm{~m}^{2}$. Hence, with a gram of Pt at present costing 26 Euro, the noble metal costs for $1 \mathrm{~km}^{2}$ amount to 2500 Euro, which will not be a cost relevant factor of such a solar cell field. For materials such as crystalline $\mathrm{Si}$, the nanoemitter distance can be increased substantially; this gain in cost would be partly explained by the necessity to form "fingers" into the material for better spectral sensitivity in the long wavelength regime of this indirect absorber. If one uses, however, less noble metals to form the semiconductor-nanoemitter junction and subsequently "caps" these metals with a noble metal for photoelectrocatalytic operation, an additional potential for a further pronounced cost reduction will result.

\section{Results and discussion}

\subsection{Si based photoelectrocatalytic nanoemitter cells}

For light-induced $\mathrm{H}_{2}$ generation, p-type material is used, whereas the first photovoltaic systems were based on $\mathrm{n}-\mathrm{Si}^{71} \mathrm{Si}$ was used first because it forms a passivating oxide and, under illumination at increased anodic potentials in a fluoride containing electrolyte, a nanoporous oxide layer forms that is well-suited as a template for (photo)electrodeposition of catalysts into the oxide pores. From Fig. 8, it can be seen that the integral oxide thickness during photocurrent oscillations in $0.1 \mathrm{M} \mathrm{NH}_{4} \mathrm{~F}$ varies between 17 and 27 monolayers (ML), corresponding to about $8 \mathrm{~nm}-$ $12 \mathrm{~nm}$ thickness (using $0.45 \mathrm{~nm}$ for $1 \mathrm{ML}$ silicon oxide ${ }^{72}$ ). To allow the strong current modulation on an average background thickness of $10 \mathrm{~nm}$, conductive channels have to be postulated, ${ }^{73}$ through which an electrical contact between electrolyte and the $\mathrm{Si}$ substrate is established. These nanopores have indeed been observed and an example is given in Fig. 9. In Fig. 9a,

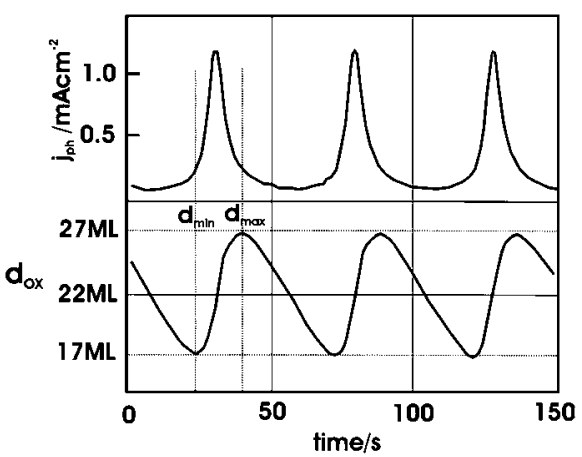

Fig. 8 Chronometric profiles of the current (upper curve) and the integral oxide thickness (lower curve) on $\mathrm{n}$-Si(111) samples, as determined by in situ FTIR, with calibration of the oxide signal by charge flow and anodic oxide formation in phthalate buffer solution; $0.1 \mathrm{M} \mathrm{NH}_{4} \mathrm{~F}$, potential $+6 \mathrm{~V}$ (SCE), light intensity $100 \mathrm{~mW} \mathrm{~cm}^{-2} ; d_{\min }$ and $d_{\max }$ denote the situations where the integral oxide thickness reaches its minimum and maximum, respectively.

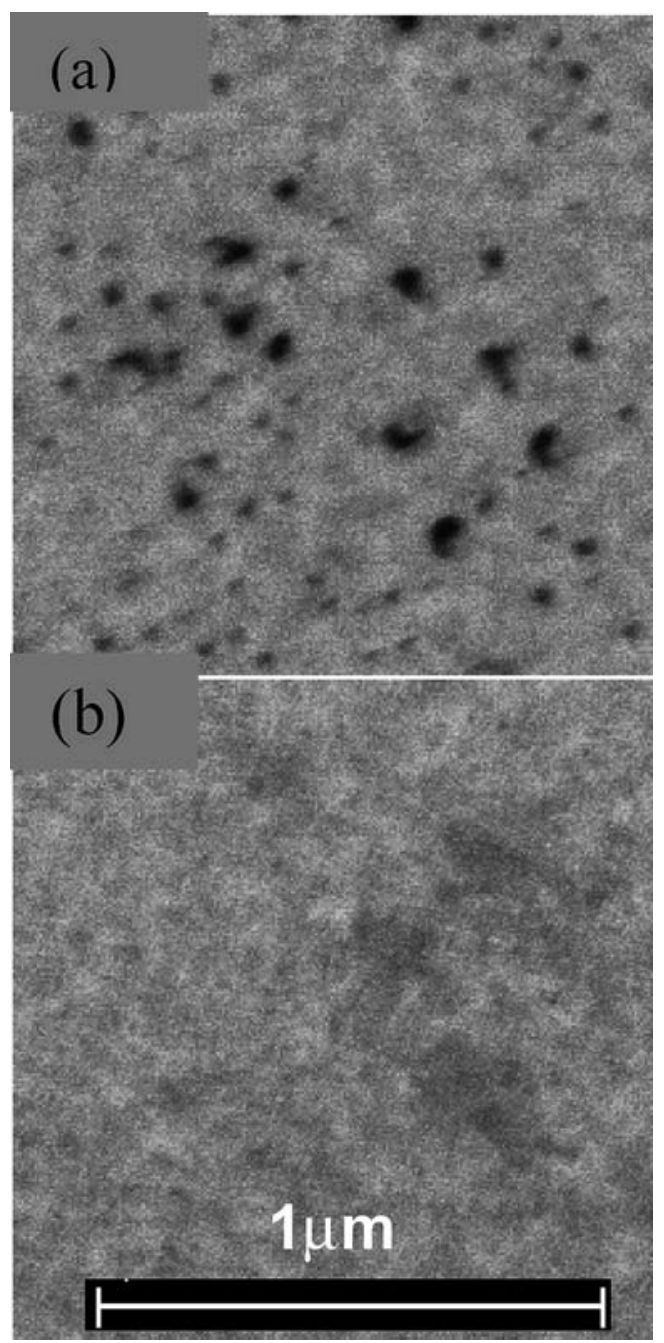

Fig. 9 High resolution scanning electron micrographs for sample emersion at two different phases of the oscillating current; (a) emersion at the increasing branch of the current where the oxide thickness is smallest, (b) emersion at the decreasing branch where the oxide thickness is at its maximum 
pronounced pores with high contrast are observed, indicating that electrical contact with the Si substrate through these pores drives the Si dissolution current that results in oxide formation. For emersion after the current maximum (Fig. 9b), the sample appears passivated. The origin of the very small remnant current could be due to ultrasmall pores that are not discernable in the image.

The concept of site selective electrodeposition (ED) is based on the passivating behaviour of the oxide outside the nanopores and the selective filling of these pores with noble metals. Before $\mathrm{ED}$, the pores have been deepened in alkaline electrolyte using an electrochemical process, because the alkaline chemical etching of $\mathrm{Si}(100)$ through the pores resulted in inverse pyramid formation. The resulting surface appearance after (i) oxide matrix template formation, (ii) pore deepening via alkaline electrochemistry and (iii) etching of the oxide in HF that leaves the Si substrate almost unaffected is revealed in Fig. 10, where a contact mode AFM image is displayed. Although the depth of the pores in the $\mathrm{Si}$ substrate is of the order of only $10 \mathrm{~nm}$, the process improves the efficiency of the photovoltaic photoelectrochemical solar cell from about $8 \%$ to above $10 \%$.

The third step in the device preparation consists of Pt ED from a hexachloride solution into the pores. For n-Si, ED was done at potentials negative to the flatband, which is at $-0.55 \mathrm{~V}$ (SCE). Finally, in contact with acidic $\mathrm{I}^{-} / \mathrm{I}_{3}{ }^{-}$redox electrolyte, efficiencies of $11 \%-11.5 \%$ have been obtained. ${ }^{69}$ These efficiencies were obtained upon illumination with a W-I lamp, which has a lower radiation temperature compared to the sun, which results in a shift of the photon flux maximum towards lower energies, thus reducing the excess energy losses. Therefore, these efficiencies are somewhat higher than those that would have been obtained by solar insolation.

For photoelectrocatalytic operation, $\mathrm{Pt}$ and $\mathrm{Rh}$ were photoelectrodeposited by a mixed potentiostatic and chronoamperometric experiment, as shown in Fig. 11. The chronoamperometric treatment at $-0.6 \mathrm{~V}$ shows a photocurrent

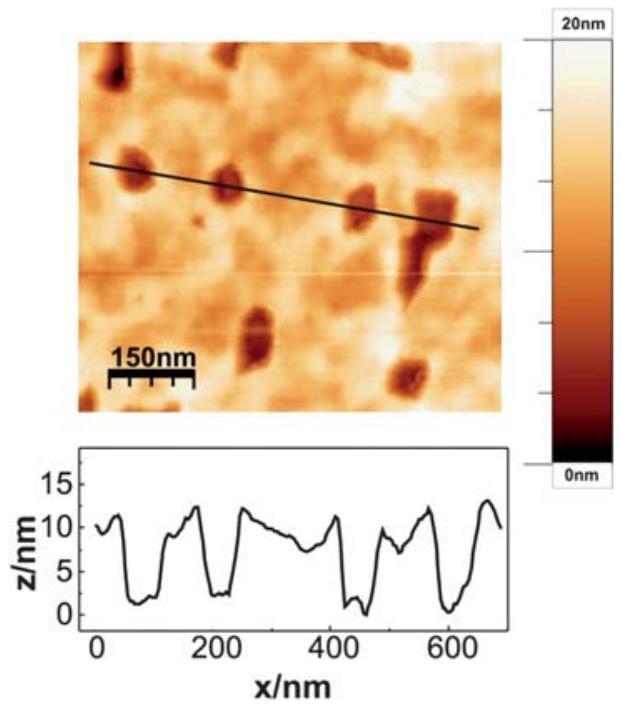

Fig. 10 Contact mode AFM micrographs after electrochemical etching of $\mathrm{Si}$ through the porous matrix in $4 \mathrm{M} \mathrm{NaOH}$ for $10 \mathrm{~min}$ at $-0.85 \mathrm{~V} /$ $\mathrm{SCE}$ ); subsequent oxide etching in $25 \% \mathrm{HF}$ for $10 \mathrm{~s}$; left: top view; right: cross sectional view.

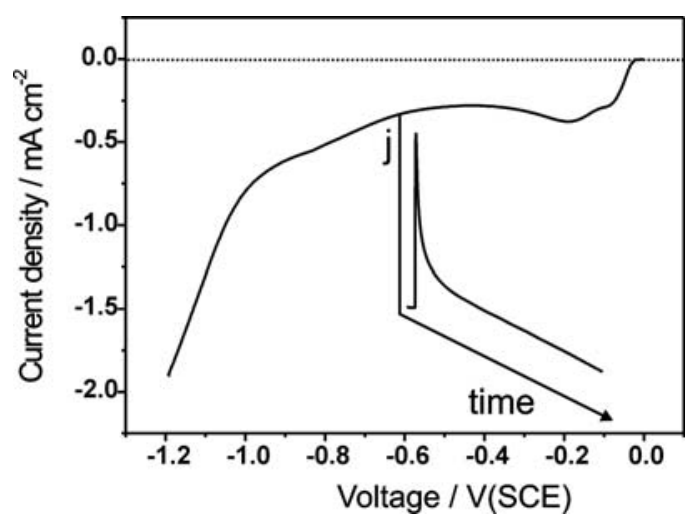

Fig. 11 Procedure for Pt photoelectrodeposition into nanopores of the oxide on $\mathrm{p}$ - $\mathrm{Si}$, formed during current oscillations in dilute $\mathrm{NH}_{4} \mathrm{~F}$ solution; solution composition: $1 \mathrm{mM} \mathrm{PtCl}_{6}^{2-}, 0.1 \mathrm{M} \mathrm{K}_{2} \mathrm{SO}_{4}, \mathrm{pH} 3.8$.

decay according to the Cottrell equation ${ }^{74}$ that is typical for diffusion limited behaviour. Fig. 12 shows the nanoporous oxide matrix and the site selective photodeposition of Pt. It can be seen in Fig. 12a that the pores are rectangularly shaped and closer inspection of the Pt deposits shows a mushroom-type appearance which is probably related to lateral overgrowth of filled pores because the sizes of the $\mathrm{Pt}$ islands are somewhat larger than those of the pores. Fig. 13 shows a photocurrent-voltage characteristic for devices made with $\mathrm{Pt}$ and $\mathrm{Rh}$ nanoemitters. It is obvious that current saturation does not occur within the displayed potential range, indicating pronounced losses in the devices. Also, the achieved photovoltage is low $(<0.2 \mathrm{~V})$ and the photocurrent onset is sluggish, as is typical for surface recombination. ${ }^{75}$ As Fig. 14 demonstrates, the $\mathrm{p}-\mathrm{Si} / \mathrm{oxide} / \mathrm{Pt}-\mathrm{Rh} / \mathrm{H}_{2}-\mathrm{H}^{+}$system is characterized by a small contact potential difference between the Si Fermi
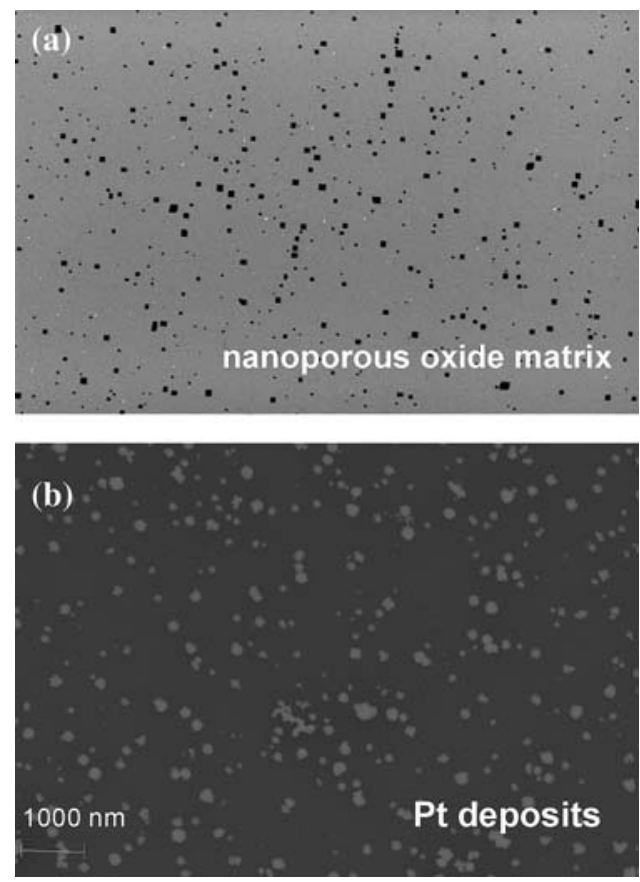

Fig. 12 HRSEM images of porous silicon oxide on p-Si(100) (Fig. 12a) and of Pt deposits after the procedure shown in Fig. 10 (Fig. 12b). 


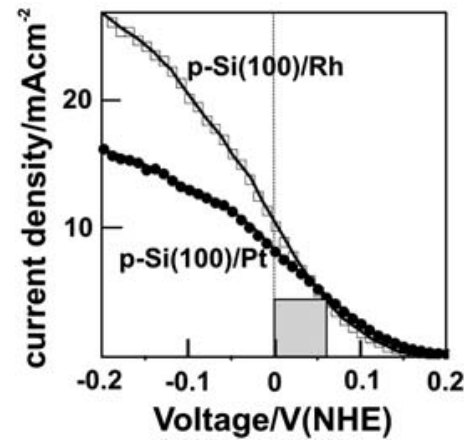

Fig. 13 Photocurrent-voltage characteristics of $\mathrm{p}$-Si/porous silicon oxide/Pt-Rh/ $\mathrm{H}_{2} \mathrm{SO}_{4}$ electrocatalysis cell; light intensity: $100 \mathrm{mWcm}^{-2}$, W-I lamp; electrolyte: $1 \mathrm{M} \mathrm{H}_{2} \mathrm{SO}_{4}$.

level and the hydrogen redox potential. The flatband of the $\mathrm{Si} / \mathrm{Rh}$ structure $^{76}$ has been determined to be $+0.2 \mathrm{~V}$ (SCE) at a $\mathrm{pH}$ of 2 . The deduced energy scheme is presented in Fig. 14, where the contact potential difference between the $\mathrm{p}-\mathrm{Si} / \mathrm{Pt}-\mathrm{Rh}$ Fermi level and NHE is taken to be $0.4-0.5 \mathrm{eV}$. The photovoltages in Fig. 13 are smaller by about $0.2 \mathrm{~V}$ than the achievable value, indicating again substantial losses in activity at low overpotentials. This is indicated in Fig. 14 by the downward movement of the electron quasi Fermi level near the surface, which is a result of the excess carrier concentration decrease due to surface and/or interface recombination. Recently, we have prepared so-called colored nanoporous $\mathrm{Si}$ by a mixed chemical-electrochemical method. ${ }^{77}$ Upon noble metal photoelectrodeposition onto these $\mathrm{p}-\mathrm{Si}$ samples, photovoltages close to $0.4 \mathrm{~V}$ were obtained for the lightinduced $\mathrm{H}_{2}$ evolution reaction. In addition, the photocurrent saturated at about $-0.2 \mathrm{~V}$ (NHE) and the photocurrents were higher due to increased quantum efficiency. It should be noted that for the first photoelectrocatalytic structures on planar $\mathrm{p}-\mathrm{Si}$ shown here, the pore deepening process that improved the photovoltaic device (based on $\mathrm{n}-\mathrm{Si}$ ) has not been applied. It is known that noble metal deposition is accompanied by silicon oxide formation. ${ }^{78}$ The charge transfer from the Si substrate to the noble metal ion containing electrolytes can also occur at pores that exhibit an oxide at their bottom either by tunnelling
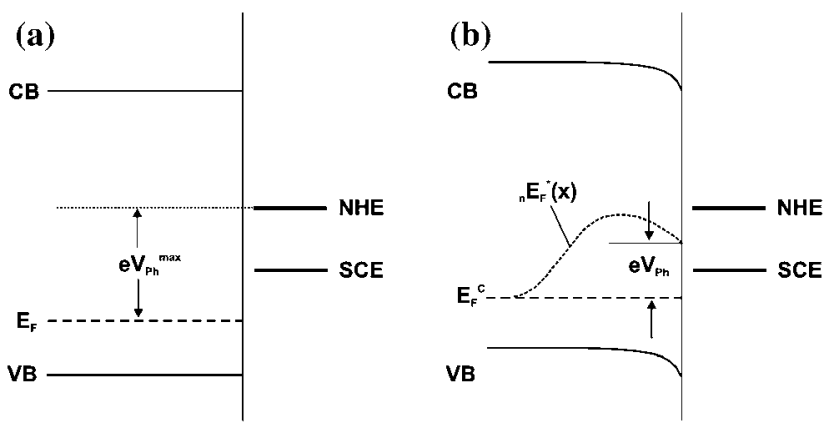

Fig. 14 Energy relations between $\mathrm{p}-\mathrm{Si}$, Pt and the hydrogen redox couple, as inferred from flatband potential measurements; ${ }_{n} E_{\mathrm{F}}{ }^{*}(\mathrm{x})$ denotes the quasi Fermi level for excess minority electrons, CB: conduction band; VB: valence band; $E_{\mathrm{F}}$ : bulk Fermi level; NHE: normal hydrogen electrode potential; SCE: saturated calomel electrode potential; $\mathrm{V}_{\mathrm{Ph}}{ }^{\text {max }}$ : maximum attainable photovoltage; (a) before contact; (b) in contact with current flow close to open circuit condition.

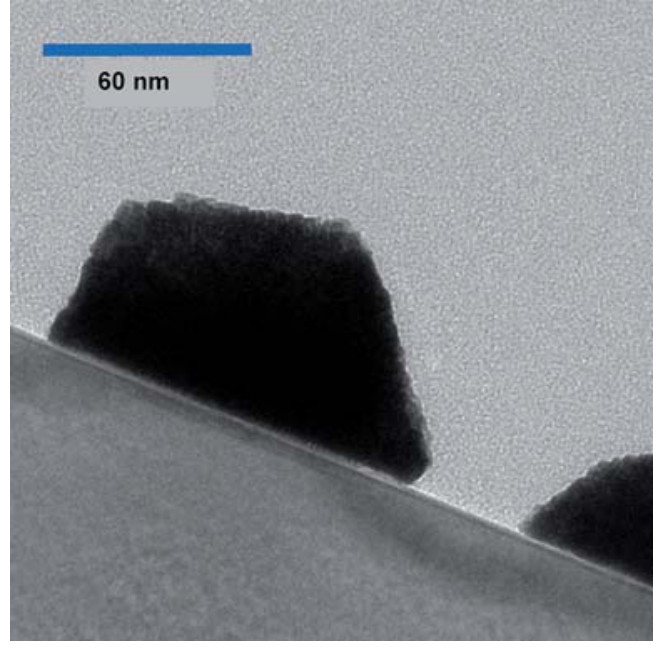

Fig. 15 Transmission electron micrograph of the interfacial cross section between $\mathrm{Si}$ and a Pt nanoisland.

through or, where charges can move, via hopping. It appears that such interfaces that are incompletely and inhomogeneously oxidized exhibit electronically deleterious behaviour and that the oxides that are formed on H-terminated Si surfaces upon metal deposition have a higher electronic quality. The pore deepening process at negative potential in alkaline solution produces $\mathrm{H}$ terminated Si before ED. Furthermore, the oxides formed before the actual ED process of the metal takes place ${ }^{79}$ could be somewhat thinner than the average oxide at the pore bottom, as can be seen from the TEM image in Fig. 15. This model experiment has been performed by $\mathrm{Pt}$ ED onto previously $\mathrm{H}$ terminated $\mathrm{Si}$. The interfacial film is about $1-1.5 \mathrm{~nm}$ thick and appears to be evenly spread across the sample surface and underneath the Pt nanoislands.

\subsection{Photoelectrocatalysis with homoepitaxial InP thin films}

InP has been applied in a half cell arrangement for light-induced $\mathrm{H}_{2}$ evolution. ${ }^{12,80}$ The reported efficiencies were obtained on bulk single crystalline material that was (111) oriented. The A-face with In lattice atom termination was used. The in situ photoelectrochemical conditioning procedure formed an intermediate indium oxide film that generated a semiconductor-oxide-electrolyte junction. ${ }^{\mathbf{8 1 , 8 2}}$ More recently, this layer has been identified by in-system photoelectron spectroscopy to consist predominantly of indium monochloride that also contains an oxidic contribution. $^{64}$

In a modified approach, we investigate the possibility of achieving efficient hydrogen evolution with InP epitaxial thin films. ${ }^{83}$ The $3 \mu \mathrm{m}$ thick films are prepared by metal organic vapour phase epitaxy (MOVPE) on a (100)-oriented InP wafer that was $\mathrm{Zn}$ doped to $10^{18} \mathrm{~cm}^{-3}$. The thin films were also $\mathrm{Zn}$ doped with a dopant concentration of $4 \times 10^{17} \mathrm{~cm}^{-3}$. Precursors in the deposition process are trimethyl indium, tertiary butylphosphine (TBP) and diethyl zinc for doping. The relation of the compounds containing group V and group III elements was 40, i.e. growth occurred with substantial $\mathrm{P}$ excess. The In rich surface is prepared by keeping the surface temperature above the sublimation temperature of the group $\mathrm{V}$ compound. ${ }^{84}$ This results in 


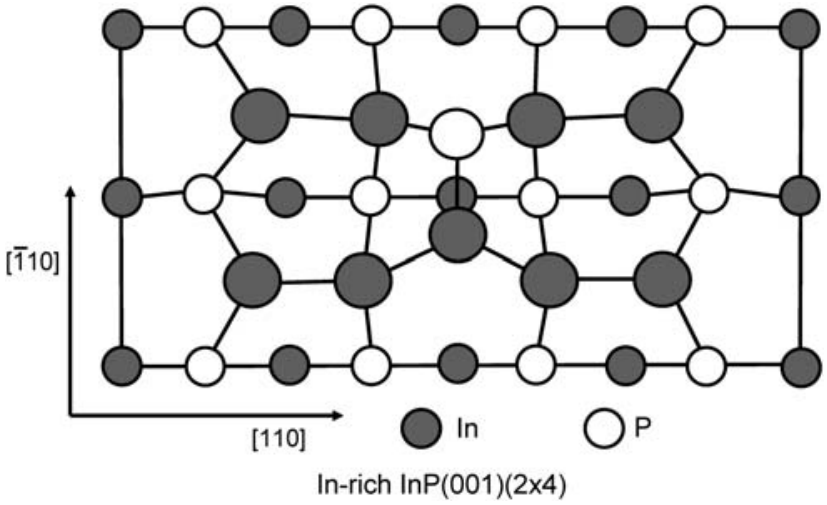

Fig. 16 Atomic arrangement of the $2 \times 4$ reconstructed In-rich InP surface; large dark circles: top In atoms; small dark circles: lower In atoms; open circles: $\mathrm{P}$ atoms.

the surface atom arrangement, determined by low-energy electron diffraction (LEED), as shown in Fig. 16. A $2 \times 4$ reconstruction is seen and 9 In top surface atoms (large dark circles) exists with only one $\mathrm{P}$ atom at the same top surface layer. ${ }^{85}$

The resulting energy band diagram of the structure is shown in Fig. 17. The larger p-type doping of the substrate results in a band bending that favors the electron movement towards and across the surface. The system is shown in contact with the $\mathrm{H}_{2} / \mathrm{H}^{+}$ redox couple, which is more negative with respect to the Fermi level of $\mathrm{p}$-InP by about $0.9 \mathrm{eV}$. The surface appearance of the homoepitaxial film shows atomic terraces, as can be seen in the tapping mode (TM) AFM image in Fig. 18. Before noble metal deposition, a surface treatment is performed that activates the catalytic behaviour. The treatment is somewhat similar to that on (111) InP surfaces, as it includes a cyclic polarization conditioning. It was found that after this treatment, the atomic steps on the surface remain discernible although the terrace widths appear somewhat smaller. ${ }^{86}$ After the deposition of Rh, the surface shows a complete metal coverage (Fig. 19a) with directly adjacent $250 \mathrm{~nm}-400 \mathrm{~nm}$ wide mesa-shaped crystallites. After operation in acidic electrolyte at the maximum power point of the solar cell, corresponding to the charge of about $10^{5}$ monolayers, the surface topography remains unaltered (Fig. 19b), thus demonstrating the stability of the system against cathodic photocorrosion. Our hitherto best output power characteristics of a thin film photoelectrocatalyst system with InP is displayed in Fig. 20. An efficiency of $\eta>12.1 \%$ is reached, demonstrating the high electronic quality of the film itself, low interface recombination at the InP/Rh boundary and a low enough metal coverage to allow efficient transmission of the incident light. Optimization strategies include the preparation of nanoisland-type nanoemitter

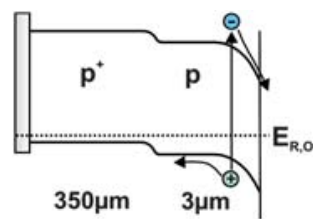

Fig. 17 Energy schematic for a $\mathrm{p}^{+}$-p-InP substrate/film junction; wafer thickness $350 \mu \mathrm{m}$; MOVPE p-InP layer thickness $3 \mu \mathrm{m}$; $\mathrm{Zn} / \mathrm{Au}$ back contact.

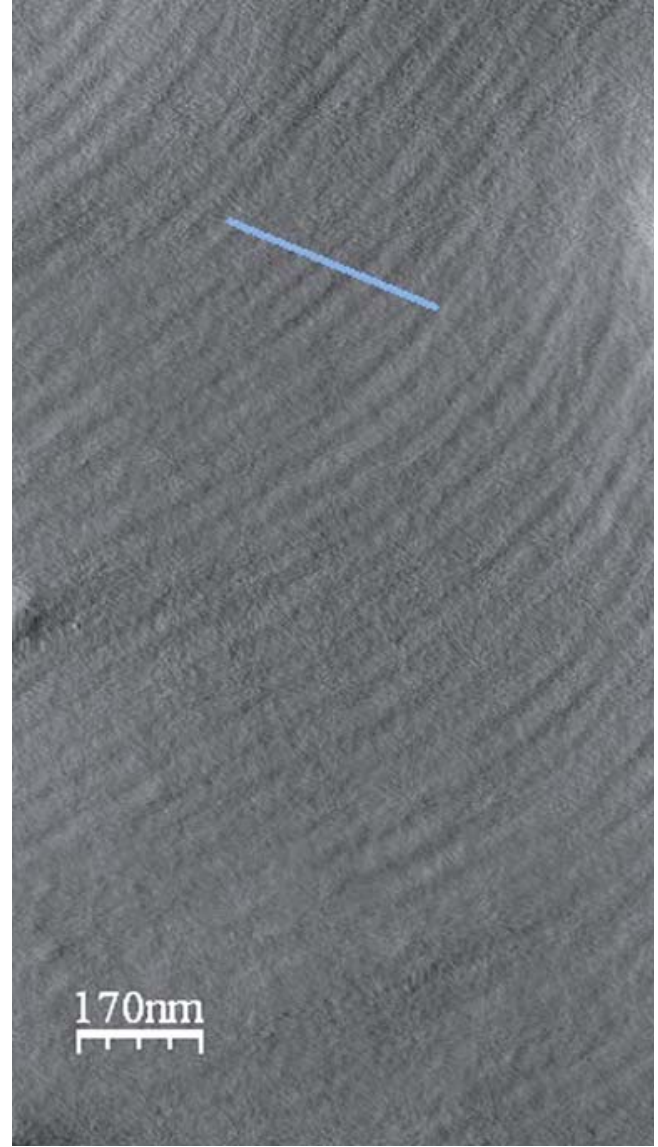

Fig. 18 Tapping mode AFM image of a homoepitaxial In-rich p-InP layer (see surface atomic arrangement in Fig. 16), showing atomic terraces with widths of about $50 \mathrm{~nm}$.

structures on an insulating, possibly lattice matched film, grown on top of the epilayer, the optimization of interface electronics and the use of non-noble metal nanoemitter materials that are capped by only a thin layer of noble metal catalysts. For technological applications, the use of thin films is mandatory and processes such as CLEFT (cleavage of epitaxial layers for transfer $^{87,88}$ or PEEL (preferentially etched epitaxial liftoff) ${ }^{89}$ should be considered.
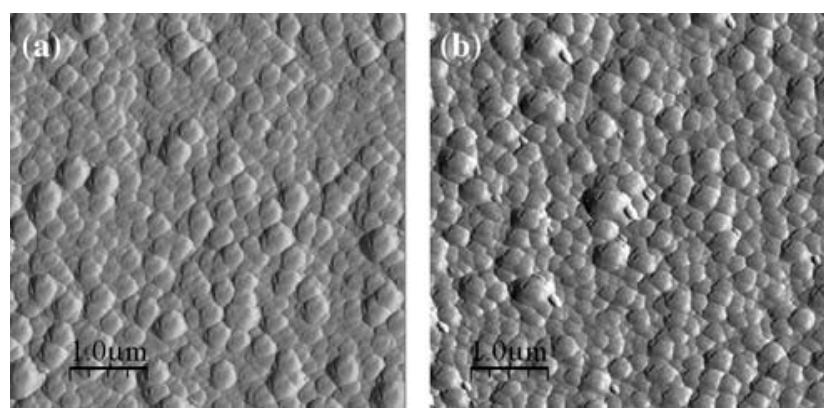

Fig. 19 TM-AFM images in amplitude mode of $\mathrm{Rh}$ deposits on homoepitaxial p-InP thin films; (a) surface topography of photoelectrodeposited film after activation procedure; (b) topography after 30 min current flow $\left(\mathrm{H}_{2}\right)$ evolution in $1 \mathrm{M} \mathrm{H}_{2} \mathrm{SO}_{4}$. 


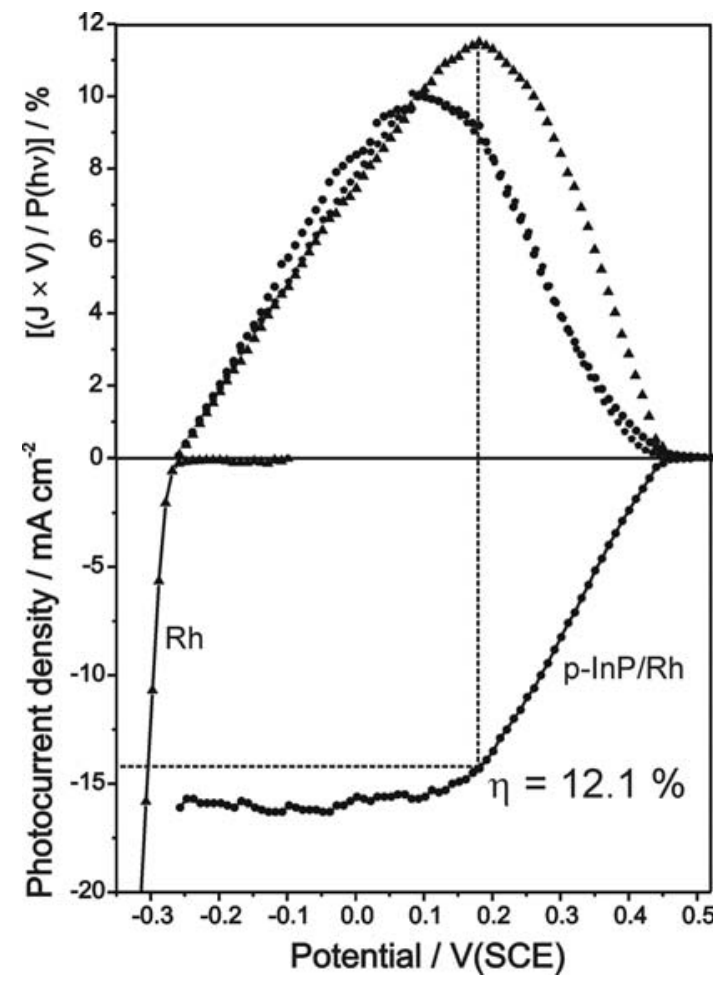

Fig. 20 Upper figure: output power characteristic of a thin film p-InP/ $\mathrm{Rh} / \mathrm{H}_{2}-\mathrm{H}^{+} / \mathrm{C}$ photoelectrocatalytic cell relative to the dark current behaviour of $\mathrm{Rh}$; lower figure: current-voltage characteristic of one of the

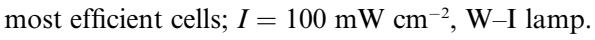

\subsection{Routes towards bio-inspired systems}

Fig. 21 shows a schematic of an envisaged bio-inspired catalytic system. Here, nanoparticle (NP) absorbers are assumed to have been deposited on a semiconducting support, which would allow rectification, thus using the system in an analogous manner to a photodiode-type solar cell. The transport along the absorber particles is taken as exciton hopping, as in the Dexter mechanism. Therefore, the NP radii are shown to overlap. The next step

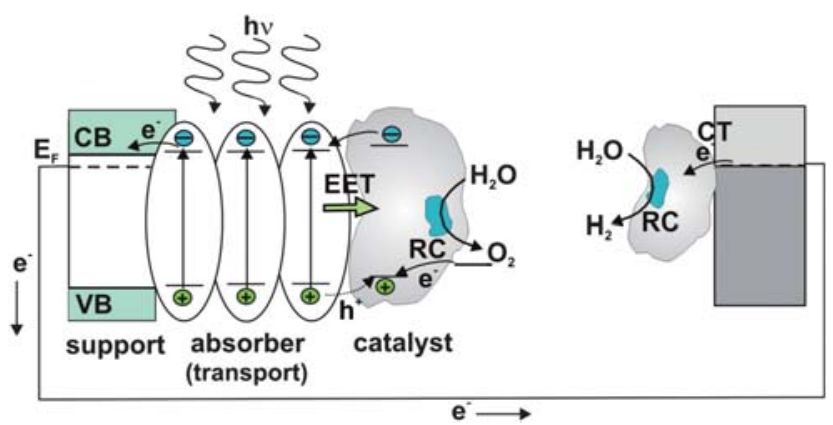

Fig. 21 Envisaged water splitting system with nanoparticle absorbers on a semiconductor, Dexter exciton transport, excitation energy transfer to the reactive site of an enzyme or macromolecule and successive water oxidation at the anode; hydrogen evolution at the cathode occurs as a dark reaction in this scheme; on the cathode side, an electron transfer step from the electrode to the molecular species has been assumed for generality. is excitation energy transfer (EET) from the surface NPs to the macromolecular catalyst center, where the reaction occurs at the reaction center (RC). This could occur by classical Marcus-type charge transfer but here, the catalytic reaction center has been assumed to be too far away for efficient tunnelling and the EET process could take place via Förster transfer, for example. The photoprocess has been assumed to occur at the anode side, where water is oxidized. The reduction to hydrogen takes place at a conducting (metallic) counter electrode that has also been modified with an appropriate catalyst. There exist, for instance, efforts to use photosystem I with a linker and a catalytic NP for light induced $\mathrm{H}_{2}$ generation. ${ }^{90}$ Although the process works in solution, it has not yet been possible to prepare electrodes where current flows to a photoelectrochemical solar cell arrangement. Hitherto, deposition of PS I onto electrodes has not led to immobilization. Therefore, the investigation of biomolecule immobilization on electrode surfaces is an important topic and in several cases such immobilization - albeit of smaller entitieshas been reported. ${ }^{91,92}$ We have studied this aspect using medically important biomolecules that bear a certain similarity to the enzymes of photosynthesis: the reverse transcriptases (RT) of retroviruses HIV 1 (human immunodifficiency virus) and AMV (avian myloblastosis virus) are both heterodimers, as are the enzymes hydrogenase and water oxidase, and their molecular weight is similar (in the range of $50-100 \mathrm{kD}$ ). We have found that the DLVO (Derjaguin Landau Verwey Overbeek) ${ }^{93}$ and nonDLVO forces ${ }^{94,95}$ play a decisive role in surface attachment. They relate to electrostatic, van der Waals interaction (DLVO) and to surface texture, steric hydration effects, for instance (nonDLVO).

Also, the isoelectric point (IP), determining the $\mathrm{pH}$ at which the molecule is neutral, is important. For the RT of HIV 1, the $\mathrm{IP}^{96}$ is between 8.5 and 9 . Hence, for physiological solutions, where the $\mathrm{pH}$ is $\sim 7$, the $\mathrm{RT}$ carries an overall positive charge. It would thus be attracted to negatively charged surface sites, which has indeed been observed on defects on $\mathrm{MoTe}_{2}$, using scanning tunnelling microscopy imaging, ${ }^{97-99}$ and on step bunched $\mathrm{Si}$ surfaces, where a negative charge along the step edges ${ }^{99}$ results in electrostatic attraction and eventually leads to short range Heitler-London van der Waals interaction. ${ }^{100,101}$ Fig. 22 shows

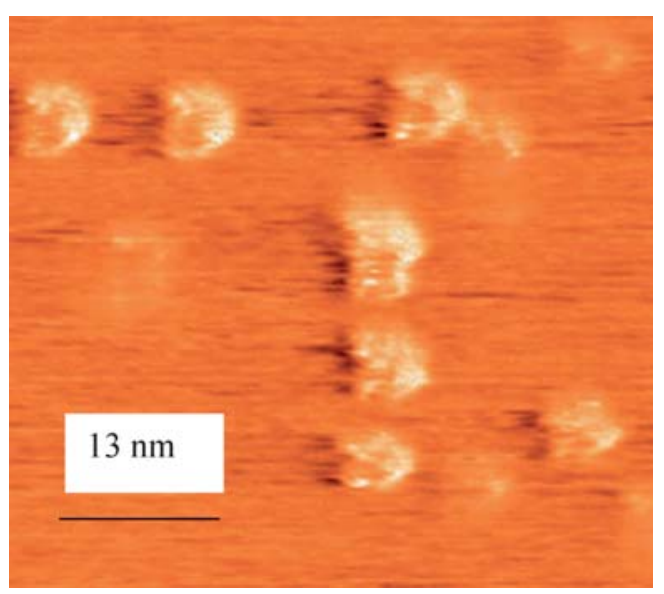

Fig. 22 STM image of a field of HIV 1 reverse transcriptases deposited from a carrier solution (see ref. 92 and 93). 
a scanning probe image of an immobilized RT on $\mathrm{MoTe}_{2}$, obtained in the constant current mode (200 pA) in air. The molecules appear to be in an upright, kidney shaped position on the surface. Such behaviour has also been found in the adsorption of the RT of AMV on step bunched Si, imaged by TMAFM. ${ }^{101}$ For the charge carrier movement from the semiconductor to the STM tip, a solvation induced detrapping of electrons on the outer polypeptides, where so-called bio-water exists, has been invoked. ${ }^{102,103}$ This mechanism also explains the findings of the Guckenberger group on moisture-induced tunnelling from insulating substrates through DNA to the STM tip. ${ }^{104}$ For charge transfer from metals or semiconductors to enzymes, this finding seems to indicate that injected electrons are not likely to easily reach the reactive sites, which are typically on the inside of the molecules, via tunnelling and hopping. Therefore, it would be worthwhile to attempt EET using a long range resonance process, as provided by the Förster mechanism. The direct use of enzymes, such as water oxidase and hydrogenase, even if they are genetically modified in terrestrial solar fuel generating systems, however, is unlikely to be successful due to their low stability. The synthesis of more stable macromolecular units appears to be a more promising route, particularly in conjunction with conducting electrodes. ${ }^{105}$

\section{References}

1 J. J. Berzelius, Ann. Chim. Phys., 1836, 61, 146.

2 W. Ostwald, Z. Phys. Chem., 1894, 15, 705.

3 F. Haber, Z. Elektrochem., 1910, 16, 244.

4 C. Bosch, in Nobel Lectures, Chemistry 1922-1941, Elsevier, Amsterdam, 1966, p. 197.

5 G. Ertl, Surf. Sci., 1967, 6, 208.

6 W. T. Grubb, Nature, 1964, 201, 699.

7 A. P. van Troostwijk and J. R. Deimann, J. Phys., 1790, 2, 130.

8 W. Nicholson and J. Carlisle, A Journal of Natural Philosophy, Chemistry and Arts, 1800, 4, 179.

9 A. Fujishima and K. Honda, Nature, 1972, 238, 37.

10 F. Di Quatro, K. Doblhofer and H. Gerischer, Electrochim. Acta, 1978, 23, 195.

11 A. J. Bard, M. S. Wrighton, in Semiconductor liquid-junction solar cells, 1977, ed. A. Heller, Electrochem. Soc., Princeton, NJ, USA Vol. 77, 1977, p. 195.

12 A. Heller and R. G. Vadimsky, Phys. Rev. Lett., 1981, 46, 1153.

13 K. Bürker, S. Fiechter, V. Eyert and H. Tributsch, J. Electrochem. Soc., 1999, 146, 261.

14 S. Menezes, H. J. Lewerenz and K. J. Bachmann, Nature, 1983, 305, 615.

15 A. Nozik, Nature, 1975, 257, 383.

16 B. O'Reagan and M. Grätzel, Nature, 1991, 353, 737.

17 J. E. Katz, T. R. Gingrich, E. A. Santori and N. Lewis, Energy Environ. Sci., 2009, 2, 103.

18 M. Späth, P. M. Sommeling, J. A. M. van Roosmalen, H. J. P. Smit, N. P. G. van der Burg, D. R. Mahieu, N. J. Bakker and J. M. Kroon, Progr. Photovolt.: Res. Appl., 2003, 11, 207.

19 IPCC report ed. B. Metz, O. R. Davidson, P. R. Bosch, R. Dave and L. A. Meyer, Cambridge University Press, Cambridge, U.K., 2007.

20 J. Deisenhofer, O. Epp, K. Miki, R. Huber and H. Michel, Nature, 1985, 318, 618.

21 J. Deisenhofer and H. Michel, Science, 1989, 245, 1463.

22 H. Ishikita, D. Stehlik, J. H. Golbeck and E.-W. Knappe, Biophys. J., 2006, 90, 1081.

23 S. Licht, J. Phys. Chem. B, 2001, 105, 6281.

24 O. Khaselev and J. A. Turner, Science, 1998, 280, 425.

25 M. Grätzel, Nature, 2001, 414, 338.

26 V. Shinkarev, B. Zybailov, I. Vassiliev and J. H. Golbeck, Biophys. J., 2002, 83, 2885.

27 J. A. Hatnean, R. Raturi, J. Lefebvre, D. B. Leznoff, G. Lawes and S. A. Johnson, J. Am. Chem. Soc., 2006, 128, 14992.
28 N. S. Lewis, Nature, 2001, 414, 589.

29 B. D. Alexander, P. J. Kulesza, I. Rutkowska, R. Solarska and J. Augustynski, J. Mater. Chem., 2008, 18, 2298.

30 A. Kay, I. Cesar and M. Graetzel, J. Am. Chem. Soc., 2006, 128, 15714 .

31 D. K. Zhong, J. Sun, H. Inumaru and D. R. Gamelin, J. Am. Chem. Soc., 2009, 131, 6086.

32 Y.-S. Hu, A. Kleiman-Shwarsctein, A. J. Forman, D. Hazen, J. N. Park and E. W. McFarland, Chem. Mater., 2008, 20, 3803.

33 M. Yagi, S. Maruyama, K. Sone, K. Nagai and T. Norimatsu, J. Solid State Chem., 2008, 181, 175.

34 R. Brimblecombe, G. F. Swiegers, G. C. Dismukes and L. Spiccia, Angew. Chem., Int. Ed., 2008, 47, 7335.

35 J. J. Concepcion, J. W. Jurss, J. L. Templeton and T. J. Meyer, J. Am. Chem. Soc., 2008, 130, 16462.

36 An energy frontier research center, entitled: "Solar Fuels and Next Generation Photovoltaics" is presently installed at The University of North Carolina at Chapel Hill; executive director is Dr Thomas J. Meyer; information on macromolecular catalyst research can be obtained from http://www.efrc.unc.edu/research/index.html.

37 A. J. Bard and M. A. Fox, Acc. Chem. Res., 1995, 28, 141.

38 S. M. Sze, K. K. Ng, Physics of Semiconductor Devices, John Wiley \& Sons, New York, 3rd edn, 2007.

39 J. H. Werner, S. Kolodinski and H. J. Queisser, Phys. Rev. Lett., 1994, 72, 3851.

40 S. Singh, W. J. Jones, W. Siebrand, B. P. Stoicheff and W. G. Schneider, J. Chem. Phys., 1965, 42, 330.

41 A. Miller and E. Abrahams, Phys. Rev., 1960, 120, 745.

42 F. P. Zamborini, L. E. Smart, M. C. Leopold and R. W. Murray, Anal. Chim. Acta, 2003, 496, 3.

43 D. L. Dexter, J. Chem. Phys., 1953, 21, 836.

44 T. Förster, Ann. Phys., 1948, 437, 55.

45 B. A. Gregg, J. Phys. Chem. B, 2003, 107, 4688.

46 M. Grätzel, Inorg. Chem., 2005, 44, 6841.

47 R. S. Knox, Photochem. Photobiol., 2003, 77, 492.

48 X. Hu, T. Ritz, A. Damjanovic, F. Autenrieth and K. Schulten, Q. Rev. Biophys., 2002, 35, 1 .

49 S. Jang, M. D. Newton and R. J. Silbey, Phys. Rev. Lett., 2004, 92, 218301.

50 J. Tersoff, Phys. Rev. Lett., 1984, 52, 465.

51 H. J. Lewerenz, J. Electroanal. Chem., 1993, 356, 121.

52 S. Ichikawa, Int. J. Hydrogen Energy, 1997, 22, 675.

53 C. Rice, S. Ha, R. I. Masel, P. Waszczuk, A. Wieckowski and T. Barnard, J. Power Sources, 2002, 111, 83.

54 H. Gerischer, Surf. Sci., 1969, 18, 97.

55 H. Gerischer, Faraday Discuss. Chem. Soc., 1980, 70, 137.

56 G. S. Higashi, Y. J. Chabal, G. W. Trucks and K. Raghavachari, Appl. Phys. Lett., 1990, 56, 656.

57 P. Dumas and Y. J. Chabal, Chem. Phys. Lett., 1991, 181, 537.

58 H. J. Lewerenz and T. Bitzer, J. Electrochem. Soc., 1992, 139, L21.

59 A. Bansal, X. L. Li, S. I. Yi, W. H. Weinberg and N. S. Lewis, J. Phys. Chem. B, 2001, 105, 10266.

60 W. J. Royea, A. Juang and N. S. Lewis, Appl. Phys. Lett., 2000, 77, 1988.

61 L. F. Mattheiss, Phys. Rev. B: Solid State, 1973, 8, 3719.

62 A. Heller, B. Miller, H. J. Lewerenz and K. J. Bachmann, J. Am. Chem. Soc., 1980, 102, 6555.

63 D. Cahen and Y. W. Chen, Appl. Phys. Lett., 1984, 45, 746.

64 K. H. Schulte and H. J. Lewerenz, Electrochim. Acta, 2002, 47, 2633.

65 Compound Semiconductor Photovoltaics, ed. R. Noufi, W. N. Shafarman, D. Cahen, L. Stolt, Materials Research Society, Warrendale, PA, USA, Symposium Proceedings, vol. 763.

66 A. Sherman, Atomic layer deposition for nanotechnology, Ivoryton Press, Ivoryton, 1st edn, 2008.

67 S. A. Campbell, S. N. Port, D. J. Schiffrin, in Semiconductor Micromachining, ed. S. A. Campbell and H. J. Lewerenz, Wiley \& Sons, New York, 1998, vol. 2.

68 M. Aggour, K. Skorupska, T. Stempel Pereira, H. Jungblut, J. Grzanna and H. J. Lewerenz, J. Electrochem. Soc., 2007, 154, H794.

69 T. Stempel, M. Aggour, K. Skorupska, A. G. Muñoz and H. J. Lewerenz, Electrochem. Commun., 2008, 10, 1184.

70 J. Tersoff, J. Vac. Sci. Technol., B, 1985, 3, 1157.

71 H. J. Lewerenz, M. Aggour, T. Stempel, M. Lublow, J. Grzanna and K. Skorupska, J. Electroanal. Chem., 2008, 619-620, 137. 
72 D. Schmeisser, personal communication.

73 H. J. Lewerenz and M. Aggour, J. Electroanal. Chem., 1993, 351, 159.

74 A. J. Bard and L. R. Faulkner, Electrochemical Methods, John Wiley \& Sons, New York, 2nd edn, 1980

75 H. J. Lewerenz and H. Jungblut, Photovoltaik. Grundlagen und Anwendungen, Springer, Berlin, 1st edn, 1995.

76 A. G. Muñoz and H. J. Lewerenz, Chem. Phys. Chem., DOI: 10.1002/cphc.200900856.

77 M. Lublow, H. J. Lewerenz, in preparation.

78 H. J. Lewerenz, Trans. Inst. Met. Finish., 2008, 86, 19.

79 For Pt, the ED follows a two-step reaction where, in the first step, $\mathrm{Pt}(\mathrm{IV})$ is reduced to $\mathrm{Pt}(\mathrm{II})$; already, in that reaction, oxide formation can occur due to hole injection into the valence band or into occupied surface states and $\operatorname{Pt}(0)$ is deposited onto the preformed oxide.

80 A. Heller, Science, 1984, 223, 1141.

81 H. J. Lewerenz, D. E. Aspnes, B. Miller, D. L. Malm and A. Heller, J. Am. Chem. Soc., 1982, 104, 3325.

82 H. J. Lewerenz, M. Lübke, S. Menezes and K. J. Bachmann, Appl. Phys. Lett., 1981, 39, 798.

83 C. Heine, H. Klemm, A. G. Muñoz, Th. Hannappel, N. Szabó and H. J. Lewerenz, patent application.

84 T. Hannappel, L. Töben and F. Wiilig, J. Electron. Mater., 2001, 30, 1425.

85 W. G. Schmidt, N. Esser, A. M. Frisch, P. Vogt, J. Bernholc, F. Bechstedt, M. Zorn, T. Hannappel, S. Visbeck, F. Willig and W. Richter, Phys. Rev. B: Condens. Matter Mater. Phys., 2000, 61, R 16335 .

86 C. Heine, H. W. Klemm, A. Munoz, K. Skorupska and H. J. Lewerenz, to be submitted.

87 J. J. Schermer, G. J. Bauhuis, P. Mulder, W. J. Meulemeesters, E. Haverkamp, M. M. A. J. Voncken and P. K. Larsen, Appl. Phys. Lett., 2000, 76, 2131.
88 R. W. McClelland, C. O. Bozler and J. C. C. Fan, Appl. Phys. Lett., 1980, 37, 560.

89 S. G. Bailey, D. M. Wilt, F. L. DeAngelo and E. B. Clark, Preferentially etched epitaxial liftoff of indium phosphide, Conference Record of the 23rd IEEE Photovoltaic Specialists Conference, Louisville, KY, 1993, p. 783.

90 J. H. Golbeck, Photosystem I (The Light-Driven Plastocyanin: Ferredoxin Oxidoreductase), Springer, Dordrecht, 1st edn, 2006.

91 S. Cosnier, Biosens. Bioelectron., 1999, 14, 443.

92 T. Yamamoto and T. Fujii, Nanotechnology, 2007, 18, 495503.

93 B. V. Derjaguin and L. D. Landau, Acta Phys. Chim. USSR, 1941, 14, 633 .

94 D. Grasso, K. Subramanian, M. Butkus, K. Strevett and J. Bergendahl, Rev. Environ. Sci. Biotechnol., 2002, 1, 17.

95 D. N. Petsev and P. G. Vekilov, Phys. Rev. Lett., 2000, 84, 1339.

96 B. Müller, T. Restle, H. Kühnel and R. S. Goody, J. Biol. Chem., 1991, 266, 14709.

97 H. Jungblut, S. A. Campbell, M. Giersig, D. J. Müller and H. J. Lewerenz, Faraday Discuss., 1992, 94, 183.

98 H. J. Lewerenz, Phys. Status Solidi B, 2008, 245, 1884.

99 K. Skorupska, M. Lublow, M. Kanis, H. Jungblut and H. J. Lewerenz, Appl. Phys. Lett., 2005, 87, 262101.

100 W. Heitler and F. London, Z. Phys. A: Hadrons Nucl., 1927, 44, 455.

101 K. Skorupska, H. J. Lewerenz and T. Vo-Dinh, Phys. Scr., 2009, 79, 065801.

102 S. A. Campbell, J. R. Smith, H. Jungblut and H. J. Lewerenz, J. Electroanal. Chem., 2007, 599, 313.

103 H. J. Lewerenz, K. Skorupska, J. R. Smith and S. A. Campbell, J. Solid State Electrochem., 2009, 13, 195.

104 R. Guckenberger, M. Heim, G. Cevc, H. F. Knapp, W. Wiegrabe and A. Hillebrand, Science, 1994, 266, 1538.

105 J. L. Dempsey, A. J. Esswein, D. R. Manke, J. Rosenthal, J. D. Soper and D. G. Nocera, Inorg. Chem., 2005, 44, 6879. 